\title{
To nurture a snake in one's bosom: aspiration of a giant right atrium thrombus after a MitraClip procedure
}

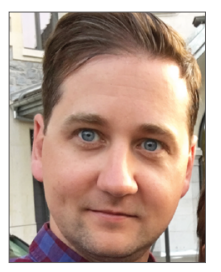

Jean-Michel Paradis*, MD; Kim O’Connor, MD; Luis Asmarats, MD; Josep Rodés-Cabau, MD

Department of Cardiology, Quebec Heart and Lung Institute, Quebec City, Quebec, Canada

This paper also includes supplementary data published online at: http://www.pcronline.com/eurointervention/142nd_issue181

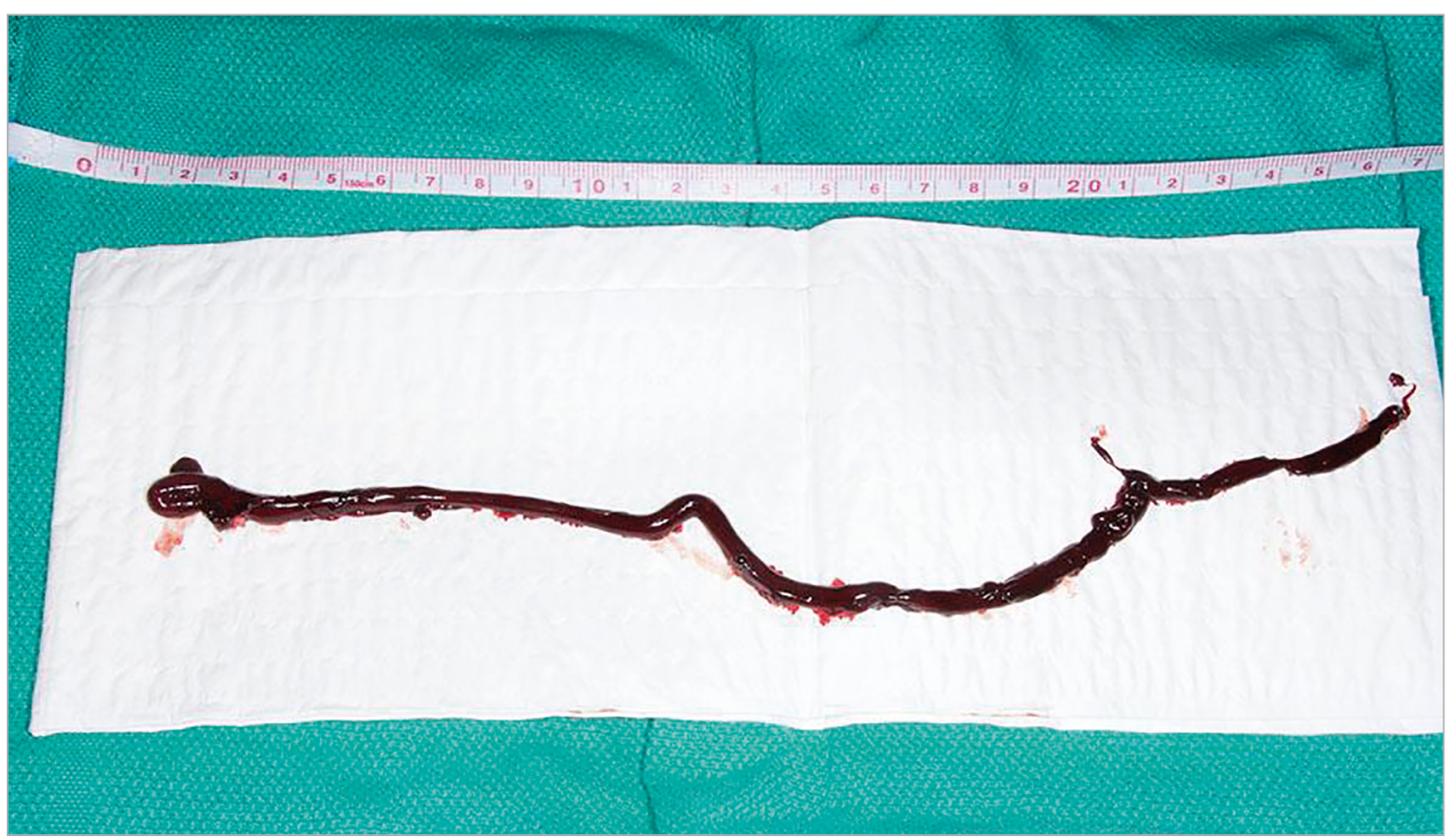

Figure 1. Picture of the catheter-related thrombus (measuring at least $27 \mathrm{~cm}$ ), which remained almost completely intact despite the aspiration process.

*Corresponding author: 2725 Chemin Sainte-Foy, Quebec City, QC G1V 4G5, Canada.

E-mail:jm.paradis@criucpq.ulaval.ca 
A 90-year-old man, with a past medical history significant for type 2 diabetes mellitus, atrial fibrillation, chronic lymphocytic leukaemia, and prior sutureless aortic valve replacement with a Perceval valve (Sorin Group, Saluggia, Italy), was admitted to our institution because of decompensated heart failure caused by severe degenerative mitral regurgitation (MR). The Heart Team deemed the patient to be at very high risk for a reoperative open heart surgery. Hence, he was referred for a MitraClip ${ }^{\circledR}$ (Abbott Vascular, Santa Clara, CA, USA) procedure. The MR was significantly reduced after the deployment of one clip. The 24 Fr steerable guide catheter was thus removed from the right femoral vein. Despite appropriate flushing of the guide catheter and adequate anticoagulation with intravenous heparin during the entire MitraClip procedure (ACT $>250 \mathrm{sec}$ ), a giant, very mobile, moulding thrombus of the steerable guide catheter was seen in the right atrium on transoesophageal echocardiography (Moving image 1). Through a long $14 \mathrm{Fr}$ sheath placed in the left femoral vein, we were able to aspirate the $27 \mathrm{~cm}$ catheter-related "snakelike" thrombus completely (Figure 1). The patient was rapidly extubated. A ventilation perfusion scan did not reveal any signs of pulmonary embolism. The patient was put on IV heparin after the procedure and then bridged to Coumadin. He was discharged home three days later. Thrombi forming within large catheters used for structural heart interventions are usually multicausal, can have catastrophic consequences and should be avoided by constantly flushing the catheters as well as by aiming for a very high level of anticoagulation during the procedure. The optimal treatment remains controversial, including anticoagulation, thrombolysis, surgical thrombectomy and percutaneous thromboaspiration ${ }^{1}$.

\section{Conflict of interest statement}

J. Rodés-Cabau has received research grants from Edwards Lifesciences, Medtronic and Heart Leaflet Technologies. The other authors have no conflicts of interest to declare.

\section{Reference}

1. Asmarats L, Fernández-Palomeque C, Martínez-Riutort JM, Bethencourt A. Right atrial thrombosis associated with hemodialysis catheter: first description of recurrence in a poorly understood problem. J Thromb Thrombolysis. 2015;39:254-7.

\section{Supplementary data}

Moving image 1. Transoesophageal echocardiogram showing a giant, very mobile thrombus located in the right atrium.

The supplementary data are published online at:

http://www.pcronline.com/

eurointervention/142nd issue/181 